\title{
PREVALENCE OF FALLS AND ASSOCIATED RISK FACTORS AMONG AGED POPULATION: COMMUNITY BASED CROSS-SECTIONAL STUDY FROM TURKEY
}

\author{
Sibel Cevizci', Şeref Uluocak², Cumhur Aslan², Gökhan Gökulu², Olgun Bilir², Coşkun Bakar \\ ${ }^{1}$ Department of Public Health, School of Medicine, Çanakkale Onsekiz Mart University, Çanakkale, Turkey \\ ${ }^{2}$ Department of Sociology, Science and Literature Faculty, Çanakkale Onsekiz Mart University, Çanakkale, Turkey
}

\section{SUMMARY}

Aim: The aim of the study was to examine the prevalence and risk factors of falls among persons aged 65 years and older in Çanakkale, Turkey.

Methods: A community based cross-sectional study was conducted between May-September 2013. A total of 1,001 elderly living in Çanakkale city centre were included into our study. The research was carried out with face-to-face interviews and survey forms. The survey form consists of seven sections: demographic characteristics, significance of ageing, daily activities, quality of life and social network in old age, use of health services and health problems, bad habits, and the European Health Impact Scale. Data analysis was performed using the SPSS software version 19.0. For data investigation the chi-square and logistic regression analyses were used.

Results: The prevalence of falls at home or outside was $32.1 \%$ among elderly in the last six months period. The prevalence of falling for women at home as well as outside was statistically significantly higher than for men $(p<0.05)$. According to multivariate analysis results the risk of falling at home or outside was increased by 2.7 times in women (95\% Cl: 1.90-3.75), by 2.1 times in those who cannot take care of themselves $(95 \%$ Cl: $1.33-3.29)$, and by 1.7 times in those who have low quality of life (95\% Cl: $1.24-2.43)$.

Conclusions: This community based cross-sectional study showed that prevalence of falling was high in aged persons living in centre of Çanakkale located in the western part of Turkey. Moreover, the risk was increased in women, those who cannot take care for themselves, and those with low standard of living.

Key words: elderly, fall, risk factors, quality of life, Çanakkale

Address for correspondence: S. Cevizci, Çanakkale Onsekiz Mart University, School of Medicine, Dept. of Public Health, Terzioglu campus, 17100, Çanakkale, Turkey. E-mail: cevizci.sibel@gmail.com

\section{INTRODUCTION}

Ageing population is a phenomenon of our time. Longevity has been the dream of humanity for thousands of years, and thus, one can consider ageing as a victory of humanity. However, the other side of the coin is not that promising. The ageing course brings many health and social problems and in ageing societies meeting these challenges becomes an obligation. Falls are only one among many challenges brought about by ageing. Aged individuals are frequently at risk of falling which may result in severe injury. There is a variety of factors that affect the incidence of falling, loss of capability and environmental reasons being at the top of the list (1). According to the Center for Disease Control and Prevention (CDC), every year, one out of every three individuals aged 65 years and above falls. Falls may cause moderately severe injuries such as hip fractures and head trauma and increase the risk of early death. In addition, the majority of falls are, in fact, preventable (2). In the United States of America in the year 2010, 2.5 million elderly people were treated in emergency services for injuries related to non-lethal falls. Of these patients more than 662,000 were admitted to hospital. The direct medical costs of injuries caused by falls have been calculated as 30 billion dollars
(2). Falls may be caused by biological or medical reasons but may also occur due to preventable behavioural and environmental factors $(3,4)$.

Although falls are an important problem for aged individuals, it is necessary to state that most of the causal risk factors are preventable. The first health services would prove to be helpful in supporting and directing individuals to continue to participate in society, especially in regions with large older population (3). Health professionals should also help to identify elderly individuals who are afraid of falling and thus avoiding physical activity, and to correctly direct them (5). However a large part of the problem lies in the organization of the environment. The cities should be planned to ease life for people with limited mobility. Such health policies must be developed and applied to prevent falls in the ageing population as an important public health step to protect the physical, mental and social health of ageing individuals.

The aim of this study is to investigate the prevalence of falls and causative risk factors, and to create the profile of the sociocultural-economic and socio-cognitive features of city dwellers aged 65 years and above in Çanakkale city centre. We presented findings from the prevalence of falls and risk factors analyses in the present study report. 


\section{MATERIALS AND METHODS}

\section{Study Population}

Çanakkale is a small city located in the western part of Turkey. The study population is limited to the elderly residing in Çanakkale city centre. In 2012, the population of the central city was 143,041 according to the Address-based Population Registration System. The gender makeup was 51\% males and $49 \%$ females. The number of people aged 65 years or above in the central city (including rural population in adjacent area of Çanakkale Municipality) is $12,308(8.6 \%)$. This population includes 5,520 males $(44.8 \%)$ and 6,788 females $(55.2 \%)$. While $77.7 \%$ of this population live in the city centre, $22.3 \%$ live in rural areas. At this point, the estimated number of people aged 65 years and above in city centre is expected to be $9,563(8,500-10,000)(6)$.

The study aimed to investigate the relation between the quality of life and the socio-cultural, economic, and health situations of elderly people in Çanakkale city centre. To this end, information concerning seven headings given above was collected. In order to calculate sample size, a sampling size formula, which is used to estimate the population rate (speed), is used. Since more than one event is being researched, the observed frequency is taken as $p=0.50$ (alpha value $95 \%$, deviation $3 \%$ ), a value which is assumed for the cases where the speed is unknown. In order to calculate the sample size, the formula which is used for the cases where the numbers of individuals in the population is known; thus the population is calculated to be 961 . In this formula the population value $(\mathrm{N})$ was assumed to be the population of people living in Çanakkale aged 65 years and above $(9,565)$. During the course of the research 1,001 people were interviewed. To reach the size of the calculated sample a simple random sampling method was used.

\section{Data Collection}

This research was carried out by experts from the Golden Years Living Centre connected to Çanakkale Municipality, and academicians from Çanakkale Onsekiz Mart University Science and Literature Faculty, Sociology Department and Medical Faculty, Public Health Department.

The research was completed between May and September 2013. The survey form was prepared by staff from Çanakkale Onsekiz Mart University Science and Literature Faculty, Sociology Department and Medical Faculty, Public Health Department.

Under the supervision of the Living Centre experts, a team of 10 interviewers for surveying was composed. At the first stage a 30-person pilot study was carried out to determine the final form of the survey. Face-to-face interview technique was used during the filling in the survey form.

Although the research made use of the elderly database created by the Çanakkale Municipality, the survey was also carried out during home visits in various neighborhoods and visits to social venues frequently visited by elderly people.

\section{Survey Forms}

This research used a survey form completed through faceto-face interviews with people aged 65 years and above. The survey form consists of various sections such as demographic characteristics, meaning attributed to ageing, daily life activities, standard of living and social network in old age, use of health services and health problems, bad habits, and the European Health Impact Scale (EUROHIS).

EUROHIS-QOL.8 which was developed in accordance with the WHOQOL-Bref scale and tested for the validity and reliability in 2010 is used for the general purpose quality of life scale for health. Both were formed of 8 general questions. It used a 5-choice Likert type questionnaire. There is a directly proportional relationship between scale score and quality of life. The scale can be graded either by taking the average of the questions, totaling the answers, or converting these totals to 100 . The scale's first question was about perception of general quality of life and the second was about perception of general health. Answering these two questions was set as a must for the calculation of the scale score. The other six questions concerned having energy for daily life (q3), satisfaction with daily life skills (q4), satisfaction with themselves (q5), satisfaction with relationships with others (q6), having money for needs (q7), and conditions of residence (q8) (7). The scale scores provide quantitative data on quality of life, so that the quality of life of different groups can be compared and risk groups can be identified.

All surveys were performed by the surveyors who were trained by teaching staff from the Sociology Department and interviews were conducted under supervision of experts from the Golden Years Living Centre. Participation in the study was voluntary and those who declined to participate were excluded. In addition, during the survey any elderly person was entitled to withdraw from the study at will. This was a joint project between the Çanakkale Municipality Golden Years Living Centre and Çanakkale Onsekiz Mart University Science and Literature Faculty, Sociology Department and Medical Faculty, Public Health Department. An informed consent was obtained from participants who voluntarily admit to participate in the study before the survey was carried out. Participants were informed about the aim of the study and how data would be evaluated and stored.

\section{Data Analysis}

Data were analyzed using the SPSS software version 19.0. Descriptive statistics (frequencies, percentages, mean, standard deviation, median, minimum and maximum values) were used to describe groups of numerical data and the basic features of the data. The variables were investigated using visual (histograms, probability plots) and analytical methods (Kolmogorov-Smirnov, Shapiro-Wilk tests) to determine whether or not they are normally distributed. The chi-square test was used to assess differences in categorical variables for univariate analyses.

Logistic regression analysis was used to examine the influence of independent variables (gender, age, having a chronic disease, physical or mental impairment, ability to sit and stand themselves, ability to move at home or outside alone, total score of quality of life, ability of self-care) upon the dependent variable (falls at home or outside). Multiple logistic regression (Backward Stepwise - Conditional) models were developed, and odds ratios (ORs) were used to evaluate risk factors associated with fallings. For the multivariate analysis, the possible factors identified with univariate analysis were further included into the logistic regres- 
sion analysis to determine independent predictors of the fallings. Hosmer-Lemeshow test for goodness of fit statistics was used to assess model fit. A 5\% type-I error level was used to infer statistical significance. Statistical significance was defined as $p<0.05$.

\section{RESULTS}

During the research 1,001 people, $55 \%$ women and $45 \%$ men, were interviewed. $56 \%$ of the participants were between $65-74$ years and $35 \%$ were between $75-84$ years of age. The mean age was $74.1 \pm 6.8$ (median 73.0, min-max: $65-100$ ). There was no statistical difference between the mean age of women and men $(p>0.05)(74.1 \pm 7.0 ; 74.1 \pm 6.7$, respectively). The education levels of $76.5 \%$ were primary school or below, and $23.5 \%$ high school and higher. There was a significant difference in education levels between genders $(p<0.05) .14 \%$ of women and $35.1 \%$ of men completed high school education or attained higher degree.

Of the respondents $16 \%$ (156 people) stated that they had fallen at home in the previous six months while $17 \%$ (165 people) had fallen outside the house. In both cases the falling events were mostly seen among women. This difference was statistically significant $(\mathrm{p}<0.05)$. Of women $20.4 \%$ had fallen at home and $21.4 \%$ had fallen outside. In men this incidence was $9.8 \%$ and $10.7 \%$, respectively. Of those who fell at home $54 \%$ reported injury. In those who fell outside of the home, the injury prevalence

Table 1. General characteristics of the participants, Çanakkale, $2013(N=1,001)$

\begin{tabular}{|c|c|c|c|c|c|c|c|}
\hline \multirow{3}{*}{ Variables } & \multirow{2}{*}{\multicolumn{2}{|c|}{ Total }} & \multicolumn{4}{|c|}{ Falls in the last six months at home or outside } & \multirow{3}{*}{$\mathbf{p}^{*}$} \\
\hline & & & \multicolumn{2}{|c|}{ No } & \multicolumn{2}{|c|}{ Yes } & \\
\hline & $\mathrm{n}$ & $\%^{\dagger}$ & $\mathrm{n}$ & $\%^{\ddagger}$ & $\mathrm{n}$ & $\%^{\ddagger}$ & \\
\hline \multicolumn{8}{|l|}{ Sex $(n=998)$} \\
\hline Female & 549 & 55.0 & 367 & 66.8 & 182 & 33.2 & \multirow{2}{*}{$<0.001$} \\
\hline Male & 449 & 45.0 & 378 & 84.2 & 71 & 15.8 & \\
\hline \multicolumn{8}{|l|}{ Age group $(n=996)$} \\
\hline $65-74$ years & 516 & 51.8 & 400 & 77.5 & 116 & 22.5 & \multirow{2}{*}{0.034} \\
\hline 75 years and above & 480 & 48.2 & 344 & 71.7 & 136 & 28.3 & \\
\hline \multicolumn{8}{|l|}{ Education level $(n=998)$} \\
\hline Primary school and below & 763 & 76.5 & 556 & 72.9 & 207 & 27.1 & \multirow{2}{*}{0.020} \\
\hline High school and higher & 235 & 23.5 & 189 & 80.4 & 46 & 19.6 & \\
\hline \multicolumn{8}{|l|}{ Marital status $(n=998)$} \\
\hline Married & 551 & 55.2 & 434 & 78.8 & 117 & 21.2 & \multirow{2}{*}{0.001} \\
\hline Single & 447 & 44.8 & 311 & 69.6 & 136 & 30.4 & \\
\hline \multicolumn{8}{|l|}{ Having a child $(n=998)$} \\
\hline Yes & 936 & 93.8 & 698 & 74.6 & 238 & 25.4 & \multirow{2}{*}{0.829} \\
\hline No & 62 & 6.2 & 47 & 75.8 & 15 & 24.2 & \\
\hline \multicolumn{8}{|l|}{ Living places $(n=998)$} \\
\hline In own home & 732 & 73.4 & 557 & 76.1 & 175 & 23.9 & \multirow{4}{*}{0.012} \\
\hline In a rent place & 155 & 15.5 & 115 & 74.2 & 40 & 25.8 & \\
\hline In a nursing home & 21 & 2.1 & 17 & 81.0 & 4 & 19.0 & \\
\hline Living with children and relatives & 90 & 9.0 & 56 & 62.2 & 34 & 37.8 & \\
\hline \multicolumn{8}{|l|}{ Job status $(n=996)$} \\
\hline Yes & 29 & 2.9 & 25 & 86.2 & 4 & 13.8 & \multirow{2}{*}{0.194} \\
\hline No & 967 & 97.1 & 718 & 74.3 & 249 & 25.7 & \\
\hline \multicolumn{8}{|l|}{ Social assurance $(n=998)$} \\
\hline Yes & 949 & 95.1 & 716 & 75.4 & 233 & 24.6 & \multirow{2}{*}{0.011} \\
\hline No & 49 & 4.9 & 29 & 59.2 & 20 & 40.8 & \\
\hline \multicolumn{8}{|l|}{ Smoking $(n=995)$} \\
\hline Yes & 160 & 16.1 & 133 & 83.1 & 27 & 16.9 & \multirow{2}{*}{0.007} \\
\hline No & 835 & 83.9 & 609 & 72.9 & 226 & 27.1 & \\
\hline
\end{tabular}

${ }^{\dagger}$ Column percentage, ${ }^{\ddagger}$ row percentage, ${ }^{*}$ chi-square test. 
Table 2. Daily living activities of the participants, Çanakkale, $2013(N=1,001)$

\begin{tabular}{|c|c|c|c|c|c|c|c|}
\hline \multirow{3}{*}{ Variables } & \multirow{2}{*}{\multicolumn{2}{|c|}{ Total }} & \multicolumn{4}{|c|}{ Falls in the last six months at home or outside } & \multirow{3}{*}{$\mathrm{p}^{*}$} \\
\hline & & & \multicolumn{2}{|c|}{ No } & \multicolumn{2}{|c|}{ Yes } & \\
\hline & $\mathrm{n}$ & $\%^{\dagger}$ & $\mathrm{n}$ & $\%^{\ddagger}$ & $\mathrm{n}$ & $\%^{\ddagger}$ & \\
\hline \multicolumn{8}{|c|}{ Ability to feed themselves $(n=997)$} \\
\hline Yes & 833 & 83.6 & 649 & 77.9 & 184 & 22.1 & \multirow{3}{*}{$<0.001$} \\
\hline Partly & 73 & 7.3 & 45 & 61.6 & 28 & 38.4 & \\
\hline No & 91 & 9.1 & 51 & 56.0 & 40 & 44.0 & \\
\hline \multicolumn{8}{|c|}{ Ability to maintain personal hygiene themselves $(n=996)$} \\
\hline Yes & 873 & 87.7 & 679 & 77.8 & 194 & 22.2 & \multirow{3}{*}{$<0.001$} \\
\hline Partly & 65 & 6.5 & 35 & 53.8 & 30 & 46.2 & \\
\hline No & 58 & 5.8 & 30 & 51.7 & 28 & 48.3 & \\
\hline \multicolumn{8}{|c|}{ Ability to sit and stand themselves $(n=996)$} \\
\hline Yes & 908 & 91.2 & 700 & 77.1 & 208 & 22.9 & \multirow{3}{*}{$<0.001$} \\
\hline Partly & 48 & 4.8 & 22 & 45.8 & 26 & 54.2 & \\
\hline No & 40 & 4.0 & 22 & 55.0 & 18 & 45.0 & \\
\hline \multicolumn{8}{|c|}{ Ability to dress themselves $(n=996)$} \\
\hline Yes & 904 & 90.8 & 697 & 77.1 & 207 & 22.9 & \multirow{3}{*}{$<0.001$} \\
\hline Partly & 44 & 4.4 & 22 & 50.0 & 22 & 50.0 & \\
\hline No & 48 & 4.8 & 25 & 52.1 & 23 & 47.9 & \\
\hline \multicolumn{8}{|c|}{ Ability to move at home alone $(n=997)$} \\
\hline Yes & 912 & 91.5 & 699 & 76.6 & 213 & 23.4 & \multirow{3}{*}{$<0.001$} \\
\hline Partly & 44 & 4.4 & 24 & 54.5 & 20 & 45.5 & \\
\hline No & 41 & 4.1 & 22 & 53.7 & 19 & 46.3 & \\
\hline \multicolumn{8}{|c|}{ Ability to move outside the house alone $(n=956)$} \\
\hline Yes & 837 & 84 & 649 & 77.5 & 188 & 22.5 & \multirow{3}{*}{$<0.001$} \\
\hline Partly & 77 & 7.7 & 46 & 59.7 & 31 & 40.3 & \\
\hline No & 42 & 4.2 & 26 & 61.9 & 16 & 38.1 & \\
\hline
\end{tabular}

${ }^{\dagger}$ Column percentage, ${ }^{\ddagger}$ row percentage, * chi-square test.

was $61 \%$. What the injuries were was not questioned. In this study the cases of falls at home and outside were evaluated together for univariate and logistic regression analysis. In the previous six months the number of people who had experienced falls at home or outside was $321(32.1 \%)$.

Univariate analysis results provided sufficient data to make comparisons between different groups such as men and women; between individuals aged 75 years and above, and 65-74 years; between individuals with different level of education: primary school and below and high school and higher; between single, widowed or divorced individuals, and married individuals; between those who don't smoke and those who do (Table 1).

The study also suggests that those who do not or partially do walk at home or outside and those who cannot or partially can take care of their daily needs have a greater tendency to fall compared to those who can do so (Table 2). Those with at least one chronic disease and those with physical and mental impairment were observed to fall more frequently. According to the EUROHISQOL 8 scale, the elderly people with lower quality of life were observed to have more falling incidents (Table 3 ).
According to backward stepwise (conditional) logistic regression analysis results, the most appropriate model was observed to be the one based on gender, age, presence of chronic disease, physical or mental impairment, ability to bath by themselves, ability to sit and stand by themselves, ability to dress by themselves, ability to move outside of the house alone, total quality of life scores, and care needs linked to ageing and disease. According to the analysis results, the fit-to-model test of the data was valid (Nagelkerke R Square: 0.137, Hosmer and Lemeshow ChiSquare: 6.611, p: 0.251). According to multivariate analysis results the risk of falling in or outside the home was increased by 2.7 times in women (95\% CI: 1.90-3.75), by 2.1 times in those who cannot look after themselves (95\% CI: 1.33-3.29), and by 1.7 times in those with low quality of living (95\% CI: 1.24-2.43) (Table 4).

\section{DISCUSSION}

This research showed that the factors identified by univariate analysis as affecting prevalence of falls within the home and 
Table 3. Disease status and quality of life scores of the participants, Çanakkale, $2013(N=1,001)$

\begin{tabular}{|c|c|c|c|c|c|c|c|}
\hline \multirow{3}{*}{ Variables } & \multirow{2}{*}{\multicolumn{2}{|c|}{ Total }} & \multicolumn{4}{|c|}{ Falls in the last six months at home or outside } & \multirow{3}{*}{$\mathrm{p}^{*}$} \\
\hline & & & \multicolumn{2}{|c|}{ No } & \multicolumn{2}{|c|}{ Yes } & \\
\hline & $\mathrm{n}$ & $\%^{\dagger}$ & $\mathrm{n}$ & $\%^{\ddagger}$ & $\mathrm{n}$ & $\%^{\ddagger}$ & \\
\hline \multicolumn{8}{|c|}{ Having a chronic disease $(n=996)$} \\
\hline Yes & 854 & 85.7 & 618 & 72.4 & 236 & 27.6 & \multirow{2}{*}{$<0.001$} \\
\hline No & 142 & 14.3 & 125 & 88.0 & 17 & 12.0 & \\
\hline \multicolumn{8}{|c|}{ Physical or mental impairment $(n=993)$} \\
\hline Yes & 130 & 13.1 & 85 & 65.4 & 45 & 34.6 & \multirow{2}{*}{0.009} \\
\hline No & 863 & 86.9 & 657 & 76.1 & 206 & 23.9 & \\
\hline \multicolumn{8}{|c|}{ Having a cancer diagnosis $(n=994)$} \\
\hline Yes & 41 & 4.1 & 30 & 73.2 & 11 & 26.8 & \multirow{2}{*}{0.836} \\
\hline No & 953 & 95.9 & 711 & 74.6 & 242 & 25.4 & \\
\hline \multicolumn{8}{|c|}{ EUROHIS-QOL.8 total score $(n=979)$} \\
\hline 69.99 point and below & 462 & 47.2 & 308 & 66.7 & 154 & 33.3 & \multirow{2}{*}{$<0.001$} \\
\hline 70.00 point and above & 517 & 52.8 & 428 & 82.8 & 89 & 17.2 & \\
\hline
\end{tabular}

${ }^{\dagger}$ Column percentage, ${ }^{\ddagger}$ row percentage, ${ }^{*}$ chi-square test

Table 4. Regression coefficients and odds ratios (95\% Cls) for risk factors associated with falls, Çanakkale, 2013

\begin{tabular}{|c|c|c|c|c|}
\hline \multirow{2}{*}{ Constant } & $\beta$ value & OR & $95 \% \mathrm{Cl}$ & $p^{*}$ \\
\hline & -2.201 & 0.11 & - & $<0.001$ \\
\hline \multicolumn{5}{|l|}{ Sex } \\
\hline Male (0) & & & 1.0 & \multirow{2}{*}{$<0.001$} \\
\hline Female (1) & 0.981 & 2.67 & $1.90-3.75$ & \\
\hline \multicolumn{5}{|l|}{ Ability to sit and stand themselves } \\
\hline Yes $(0)$ & & & 1.0 & \multirow{2}{*}{0.053} \\
\hline No (1) & 0.676 & 1.97 & $0.99-3.91$ & \\
\hline \multicolumn{5}{|l|}{ Ability to look after themselves } \\
\hline Yes $(0)$ & & & 1.0 & \multirow{2}{*}{0.001} \\
\hline No (1) & 0.737 & 2.09 & $1.33-3.29$ & \\
\hline \multicolumn{5}{|l|}{ EUROHIS-QOL.8 total score } \\
\hline High (70.00 point and above (0)) & & & 1.0 & \multirow{2}{*}{0.001} \\
\hline Low (69.99 point and below (1)) & 0.552 & 1.74 & $1.24-2.43$ & \\
\hline
\end{tabular}

${ }^{\star}$ Backward stepwise (conditional) logistic regression analysis; OR: Odds ratio; Cl: Confidence interval.

outside were female gender, advanced age, low educational level, living alone, inability to meet daily needs, walking at home or outside alone, presence of chronic disease or physical and mental impairment, and low quality of life (Table 1-3). However, since the relationships of falling incidents with results are more complicated than the variables may explain, there was a need for logistic regression analysis. The results of this analysis found that the independent variables explaining falls at home or outside in our working group were gender (female), ability to care for oneself (cannot care) and low quality of life scores (Table 4).

Our study results show that the prevalence of falling among elderly living in Çanakkale, with a high density ageing population, was high. Studies in various parts of the world show that every year one third of old people are exposed to falls, and have reported a variety of risk factors to explain this situation $(8,9)$.
In Taiwan, a cross-sectional study found that the rate of falls in the previous year was $21 \%$. In this study female gender, short height, low weight, central obesity, physical weakness, multivitamin use, and hyperglycemia were found to be the risk factors for falling; insufficient vitamin D was not related to falling (8). In another Taiwan study the incidence of falling was $14.5 \%$, with the incidence of repeated falls of $6 \%$. This study identified the sight loss, low activity levels outside the home, hypothyroidism or parathyroidism as the risk factors related to falling. Weakness, short height, and sedative/hypnotic medication use were the risk factors related to repeated falls. A pre-monitoring case of fall was observed to be related with the cases of falls occurring in a one year monitoring period and other repeated fall cases (10). In a yearly geriatric health check-up for individuals aged 65 years and above, Lin et al. found that the incidence of falls in the previous 
year was $22.7 \%$ (9). Accordingly, another Taiwan study suggested that female gender, large waist circumference, advanced age, and weak sight were the risk factors related to falls (9). According to the literature these studies examining falls and risk factors focused on individuals aged 65 years and above who attend hospital for yearly health check-ups (8-10).

In a Portuguese study the relationship of insomnia and daytime drowsiness to falling was investigated and it was found that $14.4 \%$ of ageing individuals had fallen once and $11.9 \%$ repeatedly. The incidence of falling was found to be related to the risk factors such as female gender, the age above 80 years, daytime drowsiness, and depressive symptoms (11). Another Portuguese study found that the incidence of falling was $38.6 \%$ among weak elderly individuals. Women and individuals between 60-79 years of age had the highest incidence of falls. $27.1 \%$ of the falls were observed in the bedroom, $55.9 \%$ occurred due to loss of balance, and $54.2 \%$ resulted in slight injury. $78 \%$ of individuals who fell were afraid of falling again. The incidence of falling was more than twice as high for weak, powerless, elderly individuals compared to other elderly people (12).

In an Egyptian study with 340 participants, 205 elderly individuals fell once in the previous year; $36 \%$ outside of the house and $24 \%$ on stairs inside the house. In addition, dependent elderly individuals were found to fall more frequently than those who live independently. According to the results of univariate regression analysis living alone, having a chronic disease, using medication, physical insufficiency, and being active were determined to be the risk factors with significant relationships to cases of falls. However, multivariate regression analysis results indicated that risk factors such as low level physical activity, using a walking stick or other device to aid walking and having problems in daily life activities had a statistically stronger correlation with falls (3). As falls trigger fear in elderly individuals, individuals avoiding movement becomes a public health problem $(5,13-15)$.

Elderly individuals with cognitive disorders have a higher risk of falls; a year-long prospective study of participants with cognitive disorders found that $64 \%$ fell at least once, while $41 \%$ fell at least twice. Factors such as slow reactions, balance problems, and reduced capability to move along with medication use were related to low performance on cognitive and psychological tests and to a high incidence of falls (16). In a study by Moniz-Pereira et al. falling may not be an unavoidable result of advanced age; they identified the important risk factors to be poor health situation and poor functionality. Increased physical activity can improve functionality and it may be a protective factor to prevent both episodic and repeated falls (17). In a Finnish study of 409 women aged between $70-80$ years, $68 \%$ worried about falls. In women with high anxiety about falls, the general health situation and perception of quality of life were poor and functional capability was found to be statistically lower (18).

In a report on preventing falls and injury related to falls by the Ontario Ministry of Health, it was found that the long-term exercise programmes for elderly people and some environmental changes at home for physically weaker individuals could reduce the incidence of falls and injury related to falls. They reported that use of a combination of vitamin D and calcium for elderly women, may help reduce the risk of falling by more than $40 \%$. They stated that using devices to stabilize the legs of elderly individuals outside the house in the winter would reduce falls and related injuries (19). In the USA falls are ranked first among the reasons for injury in elderly individuals. Physical and mental weakness is the most important risk factor for falls among elderly people. They reported that physical exercise programmes for elderly individuals may help improve mental and physical strength and reduce the risk of falls (20).

This paper examined the prevalence of falling in the last six months in ageing people in Çanakkale city centre. Compared to other municipalities the proportion of aged people residing in Çanakkale is high (6). The study found that $32 \%$ of the aged population had fallen at home or outside in last 6 months. This situation should not be underestimated. Half of these falls resulted in injury. As this study aimed to provide an age profile of the elderly population in Çanakkale, it does not provide more detailed information. However, the current situation calls for more detailed research on falls and risk factors. Qualitative studies of people who have experienced falls are required. However, the results of our study present important information on falls and related risk factors in elderly people. Women were observed to be more prone to falling and this is in accordance with the literature. This may be linked to the structures of the muscle-skeletal system of women. Women have a tendency to osteoporosis, which makes falls a risk for morbidity and mortality. As a result women require protective interventions to reduce falling. Advanced age is another risk factor for falls. This is in accordance with our expectations and the literature. The physical problems of advanced age make falling easier. In our study poor quality of life and not being able to perform daily activities were considered serious risk factors. There are some studies on poor quality of life and falling. Again we believe there is a relationship. Just as quality of life may be a risk for falling, falls affect quality of life. In the literature there are results which indicate that fear of falling may prevent an individual from moving. This situation consequently affects the quality of life.

Janečková et al. reported that risk factors such as gender, having children, self-perceived health, depression, activity limitations and quality of life have significant influence on positive attitudes for both older adults and their caregivers to ageing (21). Ludwig et al. indicated that lessening the burden of noncommunicable chronic diseases such as adult pneumococcal disease in Central and Eastern Europe, and Israel is so important for healthy ageing. Authors also stated that it is necessary to improve and implement preventative programmes for maintaining healthy active lifestyle such as daily activities and self-care in older age groups (22). Ležovič et al. reported that developed countries such as Slovakia need to improve long-term health care services because of their rapidly increasing ageing population (23). Turkey has not yet a developed country, but it will have the largest ageing population in the near future. Therefore, long-term health care services have to be formulated to protect the quality of life of ageing population in both developed and developing countries.

Unfortunately ageing and falling are two cases observed together in many parts of the world. In addition to health problems of elderly people, falls have the potential to cause many problems, even death. The solution of the problem is through socially and psychologically protective physician services. An elder-friendly planning, starting with cities, should be devised to support people with limitations and high age. Not just the elderly, people of all age groups should be made aware of risks of falls. Elderly people 
should be carefully monitored by the first health organizations and both the elderly and those who live with them should be informed about falls. Especially elderly people living alone should not forget that they have greater risk for falls. These elderly people should be frequently visited at home by health and social services experts and helped to eliminate fall risks in their home.

In societies with ageing populations falls are an important problem which require active surveillance systems to carefully monitor fall cases.

\section{Acknowledgements}

The authors also wish to thank all the participants of the study, project coordinator Nadide Bilir, project experts Işıl Kardeş and Ceren Turgut, interviewers Hazal Nural, Bumin Kaan Dincer, Özlem Kilisli, Hediye Salihoğlu, Seda Başok, Tarık Yılmaz, Püren Başuğur, Elvan Ecem Başel, Ezgi Eri and Yusuf Demirok. The authors are grateful to Professor Erhan Eser, from the School of Medicine, Celal Bayar University, for his invaluable advices and contributions. The authors wish to thank the Çanakkale Municipality and its staff.

\section{Funding}

This research was supported by the South Marmara Development Agency under the auspices of the Golden Years Living Centre of Çanakkale Municipality within the framework of a protocol with Çanakkale Onsekiz Mart University.

\section{Conflict of Interests}

None declared

\section{REFERENCES}

1. Daniel H, Oesch P, Stuck AE, Born S, Bachmann S, Schoenenberger AW. Evaluation of a novel photography-based home assessment protocol for identification of environmental risk factors for falls in elderly persons. Swiss Med Wkly. 2013 Nov 12;143:w13884.

2. Centers for Disease Control and Prevention [Internet]. Atlanta: CDC; 2015 [cited 2013 Nov 21]. Older adult falls: get the facts. Available from: http://www.cdc.gov/homeandrecreationalsafety/falls/adultfalls.html.

3. Kamel MH, Abdulmajeed AA, Ismail Sel-S. Risk factors of falls among elderly living in urban Suez--Egypt. Pan Afr Med J. 2013;14:26.

4. Nyman SR, Ballinger C, Phillips JE, Newton R. Characteristics of outdoor falls among older people: a qualitative study. BMC Geriatr. 2013 Nov $18 ; 13: 125$.

5. Zijlstra GA, van Haastregt JC, van Eijk JT, van Rossum E, Stalenhoef PA, Kempen GI. Prevalence and correlates of fear of falling, and associated avoidance of activity in the general population of community-living older people. Age Ageing. 2007 May;36(3):304-9.

6. Canakkale's Statistical Yearbook 2012 [Internet]. Ankara: Turkish Statistical Institute (TurkStat); 2013 [cited 2013 Dec 11]. Available from: http://www.tuik.gov.tr.

7. Eser E, Lağarlı T, Baydur H, Akkurt V, Akkuş H, Arslan E, et al. Pschometric properties of The Turkish version of the EUROHIS-Tr
(WHOQOL-8-Tr) in a Turkish population. Turkish J Public Health. 2010 Dec;8(3):136-52. (In Turkish.)

8. Wu TY, Chie WC, Yang RS, Liu JP, Kuo KL, Wong WK, et al. Factor associated with falls among community-dwelling older people in Taiwan. Ann Acad Med Singapore. 2013 Jul;42(7):320-7.

9. Lin CH, Liao KC, Pu SJ, Chen YC, Liu MS. Associated factors for falls among the community-dwelling older people assessed by annual geriatric health examinations. PLoS One. 2011 Apr 19;6(4):e18976.

10. Wu TY, Chie WC, Yang RS, Kuo KL, Wong WK, Liaw CK. Risk factors for single and recurrent falls: a prospective study of falls in community dwelling seniors without cognitive impairment. Prev Med. 2013 Nov;57(5):511-7.

11. Pereira AA, Ceolim MF, Neri AL. Association between insomnia symptoms, daytime napping, and falls in community-dwelling elderly. Cad Saude Publica. 2013 Mar;29(3):535-46. (In Portuguese.)

12. Fhon JR, Rosset I, Freitas CP, Silva AO, Santos JL, Rodrigues RA Prevalence of falls among frail elderly adults. Rev Saude Publica. 2013 Apr;47(2):266-73.

13. Kempen GI, van Haastregt JC, McKee KJ, Delbaere K, Zijlstra GA Socio-demographic, health-related and psychosocial correlates of fear of falling and avoidance of activity in community-living older persons who avoid activity due to fear of falling. BMC Public Health. 2009 Jun 2;9:170.

14. Scheffer AC, Schuurmans MJ, van Dijk N, van der Hooft T, de Rooij SE. Fear of falling: measurement strategy, prevalence, risk factors and consequences among older persons. Age Ageing. 2008 Jan;37(1):19-24.

15. Kumar A, Carpenter H, Morris R, Iliffe S, Kendrick D. Which factors are associated with fear of falling in community-dwelling older people? Age Ageing. 2014 Jan;43(1):76-84.

16. Taylor ME, Delbaere K, Lord SR, Mikolaizak AS, Brodaty H, Close JC Neuropsychological, physical, and functional mobility measures associated with falls in cognitively impaired older adults. J Gerontol A Biol Sci Med Sci. 2014 Aug;69(8):987-95.

17. Moniz-Pereira V, Carnide F, Machado M, Andre H, Veloso AP. Falls in Portuguese older people: procedures and preliminary results of the study Biomechanics of Locomotion in the Elderly. Acta Reumatol Port. 2012 Oct-Dec;37(4):324-32.

18. Patil R, Uusi-Rasi K, Kannus P, Karinkanta S, Sievänen H. Concern about falling in older women with a history of falls: associations with health, functional ability, physical activity and quality of life. Gerontology. 2014;60(1):22-30.

19. Health Quality Ontario. Prevention of falls and fall-related injuries in community-dwelling seniors: an evidence-based analysis. Ont Health Technol Assess Ser. 2008;8(2):1-78.

20. DeSure AR, Peterson K, Gianan FV, Pang L. An exercise program to prevent falls in institutionalized elderly with cognitive deficits: a crossover pilot study. Hawaii J Med Public Health. 2013 Nov;72(11):391-5.

21. Janečková H, Dragomirecká E, Holmerová I, Vaňková H. The attitudes of older adults living in institutions and their caregivers to ageing. Cent Eur J Public Health. 2013 Jun;21(2):63-71.

22. Ludwig E, Ünal S, Bogdan M, Chlíbek R, Ivanov Y, Kozlov R, et al. Opportunity for healthy ageing: lessening the burden of adult pneumococcal disease in Central and Eastern Europe, and Israel. Cent Eur J Public Health. 2012 Jun;20(2):121-5.

23. Ležovič M, Raučinová M, Kováč A, Moricová S, Kováč R. Long-term care in developed countries and recommendations for Slovak Republic. Cent Eur J Public Health. 2008 Mar;16(1):21-5.

Received June 2, 2014

Accepted in revised form February 24, 2015 